\title{
Effect of summer flush leaves of the Daimyo oak, Quercus dentata, on density, fecundity and honeydew excretion by the drepanosiphid aphid Tuberculatus quercicola (Sternorrhyncha: Aphididae)
}

\author{
IzUMI YAO \\ Department of Ecology and Systematics, Graduate School of Agriculture, Hokkaido University, Sapporo 060-8589, Japan; \\ e-mail: iyao@res.agr.hokudai.ac.jp
}

Key words. Aphididae, Drepanosiphinae, Tuberculatus quercicola, flush leaves, amino acid, reproductive diapause, honeydew, oak, Quercus dentata

\begin{abstract}
The aphid Tuberculatus quercicola (Matsumura), a non host-alternating species, lives on Daimyo oak, Quercus dentata Thumberg, and other species of oak. In summer there was a significant reduction in the total amino acid concentration in phloem sap of the host plant and fecundity of the aphids. There are two phenotypes of $Q$. dentata: one produces flush leaves in mid-July and the other does not. This study investigates the effect of the flush leaves produced by $Q$. dentata in summer on the density, fecundity and honeydew excretion by T. quercicola. Of 20 shoots on each of the study trees, 6-13 (average 8.8 shoots) produced secondary shoots with flush leaves. The number of aphids on flush leaves sharply increased by two-fold compared to that on mature leaves. The aphids reared on flush leaves were significantly larger and had a larger embryo number compared to those on mature leaves. These results suggest that the phloem sap of flush leaves has a high nutritive quality for aphids. However, in mid-summer and early autumn T. quercicola went into reproductive diapause regardless of whether it was reared on flush or mature leaves. Aphid colonies persisted until October even on trees that did not produce secondary leaves. These observations suggest that this aphid does not depend on secondary leaf production. Thus, the use of flush leaves does not enable T. quercicola to avoid nutritional stress in summer and the need for reproductive diapause.
\end{abstract}

\section{INTRODUCTION}

Seasonal deterioration in host plant quality affects the survival and reproduction of herbivores, including aphids (Awmack \& Leather, 2002). The concentrations of nitrogen and carbohydrate in phloem sap are high in spring and autumn, when leaves are growing or senescent, and low in summer when leaves are mature (Dixon, 1970). Furthermore, in summer, the decrease in water content and increase in leaf toughness are unfavourable for phytophagous insects (Feeny, 1970). Host plant alternation in aphids, which is the seasonal shift between woody (primary) and herbaceous plants (secondary), is often cited as the means by which aphids are able to optimally utilize the available nutrients (Dixon, 1998). It should be noted that host plant alternation occurs in only about $10 \%$ of aphid species (Eastop, 1973), and many of the other species live on trees or herbaceous plants throughout the season. These non hostalternating aphids use many methods to overcome poor nutritional conditions. It is suggested that galling extends the favourable conditions for some aphid species (Kennedy, 1958; Forrest, 1971; Koyama et al., 2004). In others, sexual morphs develop and produce eggs in early summer (Akimoto, 1985; Eastop, 1986; von-Dohlen \& Gill, 1989). This abbreviated life cycle may also enable them to avoid unfavourable host plant quality. Several aphid species are known to aestivate in summer. The aestivating aphids are characterized by poorly developed gonads and low fat content. Some of the aphid species living on sycamore trees, Drepanosiphum platanoidis
(Schr.) and Periphyllus testudinaceus (Fernie), enter reproductive diapause in summer and resume reproduction at the onset of autumn (Dixon, 1970). Therefore, aestivation is believed to be adaptive as it enables aphids to cope with the poor nutrition in summer.

In early summer, there can be a second bud burst, which produces what are referred to as flush leaves. Flush leaves emerge from the ends of spring shoots in summer on several tree species. These affect insect-plant interactions as well as compensate for the damage caused by herbivores and mechanical injury. The performance of the flea beetle, Argopistes coccinelliformis Csiki, is better when reared on flush leaves than on spring leaves (Inoue, 1998). Further, the mealy pine aphid, Schizolachnus pineti (F.), does not switch from parthenogenetic to sexual reproduction (Dagg, 1999). There is a higher amino acid content in the honeydew of the aphid Hyalopterus pruni (Geoffroy) reared on flush leaves than on mature leaves of victoria plum (Douglas, 1993). These examples illustrate that the nutritional quality of flush leaves is high and they are important for phytophagaous insects.

Tuberculatus quercicola, a non host-alternating aphid is associated with Daimyo oak, Quercus dentata. In May, when the nutritional quality of leaves is good, T. quercicola has a high reproductive rate. In summer, however, there is a significant reduction in the total amino acid concentration in the phloem sap, and in the body size and total embryo number of the aphid (Yao et al., 2000; Yao \& Akimoto, 2002). As the body size of aphids decreases 
their fat content increases and gonads become smaller (Yao, unpubl.), indicating that they are entering reproductive diapause. Furthermore, the role of honeydew excretion, in terms of volume of a honeydew droplet, the number of honeydew droplets and the total volume of honeydew produced, decreases in summer (Yao \& Akimoto, 2002). There are two genotypes of the host plant, Q. dentata, as: one that produces flush leaves in mid-July and the other does not. In this study, these trees are referred to as flushing and non-flushing.

This study examines the effect of flush leaves on aphid performance. It is hypothesised that flush leaves improve aphid reproduction, affect honeydew excretion and delay the onset of diapause. However, the relationship between aphid performance and the improvement in nutritional status has not been directly evaluated. This study aims to determine whether flush leaves affect the growth, honeydew excretion and reproductive diapause in $T$. quercicola, and compare the amino acid composition of phloem sap of and honeydew produced on flush and mature leaves.

\section{MATERIAL AND METHODS}

\section{Study area, aphids and trees}

The observations and experiments were carried out at a site on the Ishikari Coast, Hokkaido, northern Japan $\left(43^{\circ} \mathrm{N}, 141^{\circ} \mathrm{E}\right)$, from May to October 2000, from July to August 2001 and from June to August 2002. Bushy stands of $Q$. dentata grow along the coast. In summer, all nymphs develop into alate viviparous females, while alate males and apterous oviparous females appear in autumn. In mid-July, flush leaves usually emerge from the ends of mature (spring) shoots on flushing trees. Although there is no established molecular basis to this, it is possible that the flushing and non-flushing trees have genetically based phenotypes with different responses to spring leaf damage; the flushing trees produce flush leaves regardless of leaf damage whereas the non-flushing trees do not produce flush leaves even after severe defoliation.

\section{Population census}

The number of aphids per leaf per tree was counted on eight trees almost weekly from late May to late October 2000. Of these trees, five produced flush leaves, while three did not. On May 22, 20 shoots were randomly selected on each tree. Aphids on all the leaves (average $6.7 \pm$ SE 0.11 leaves) of each selected shoot were counted. The number of aphids per leaf per tree was calculated by averaging the aphids on all the leaves of the tree. The grand average for the five trees was the population data. The number of aphids on the flush leaves, which emerged from the end of the selected shoots, was recorded from mid-July to late October.

\section{The effects of flush leaves on the body size and reproduction of the aphid}

Five trees and three trees, average height $1.8 \mathrm{~m}$, were used for the experiments in 2000 and 2001 , respectively. A total of 18 shoots were selected on the five flushing and the three flushing trees and used for this experiment. In order to eliminate the effect of genetic differences between aphids, one aphid clone was reared on each of the study trees prior to the experiment. With the exception of one leaf, all the leaves were excised from each shoot, and all the aphids found on the remaining leaf were removed. On each study tree, 10-20 clonal third- to fourthinstar nymphs were transferred onto each of the remaining leaves on June 9, 2000 and June 18, 2001. After the transfer, each leaf was bagged in a nylon net $(33 \times 22 \mathrm{~cm})$ to prevent predation. The aphid density was maintained at a constant level of 10-20 individuals by removing some individuals. Three to four clonal alate viviparous females from each bagged leaf of each study tree were transferred onto the flush leaves near the bagged leaf in late July 2000 and early July 2001. After the transfer, all the flush leaves were bagged. The body size and reproduction of the aphids were compared using pairs of leaves.

To determine the number of embryos in each aphid, only fourth-instar nymphs were collected from each bagged leaf from June to September 2000 and from July to August 2001. All the aphids were preserved in $70 \%$ ethanol in vials. The following measurements were made on each aphid: body width, mature embryo number and total embryo number. The total numbers of embryos included mature and immature embryos, which could be identified by the presence or absence of pigmented eyes. The body width was measured using an eyepiece micrometer installed in a binocular microscope, and the number of mature and immature embryos in each female were counted after dissection. These measurements for each colony were averaged each month, and the averages were used in the analyses.

\section{Honeydew excretion}

Honeydew excretion was quantified as follows: using the bagged aphid colonies (1) the volume of a single honeydew droplet, (2) the number of honeydew droplets excreted per aphid per hour and (3) the total volume of honeydew produced per aphid per hour, were determined. There were 14 replicates and the method is described in greater detail by (Yao \& Akimoto, 2001).

\section{Collection of the phloem sap of $Q$. dentata}

Phloem sap was obtained using the EDTA-exudation technique (King \& Zeevaart, 1974). A close correlation exists between the amino acid composition of exudate samples and that of phloem samples (Weibull et al., 1990). Two trees, approximately $2.0 \mathrm{~m}$ tall, were used for this experiment, and the phloem sap was collected from the leaves on July 29, and August 25, 2001. Five flush leaves and five mature leaves were randomly selected from the two trees, and the basal part of the petiole, $1.5 \mathrm{~cm}$ long, was immersed in a microtube containing $0.2 \mathrm{ml}$ of $5 \mathrm{mM}$ EDTA solution $(\mathrm{pH} 7.0)$ for $6 \mathrm{~h}$ at $25^{\circ} \mathrm{C}$. The phloem samples were stored at $-20^{\circ} \mathrm{C}$ until analysed. A measurement of the absolute amino acid concentrations in each sample was not possible, because the sample sizes varied greatly depending on petiole size. Therefore, the total amino acid content was assumed to be $100 \%$, and subsequent calculations were made based on the relative amino acid concentrations in each sample.

\section{Collection of honeydew}

This experiment was conducted from July to August, in 2001 and 2002, using the bagged aphid colonies. In each colony, honeydew was collected from an average of $3.46( \pm 1.10, \mathrm{SD})$ aphids using a $0.5 \mu 1$ microcapillary. After the collection, each microcapillary was placed in a microtube containing $10 \mu \mathrm{l}$ distilled water. The samples were stored at $-20^{\circ} \mathrm{C}$. This experiment used a total of 15 replicates, of which 11 replicates were analysed in 2001 and 4 in 2002.

\section{Amino acid analysis}

The exudate samples were dried in vacuo and mixed with a coupling solution (ethanol : water : triethylamine : phenyl isothiocyanate $=7: 1: 1: 1 \mathrm{v} / \mathrm{v})$. After coupling for $20 \mathrm{~min}$ at room temperature, the solution was evaporated to dryness under high vacuum. Elution was carried out with the following solvent sys- 

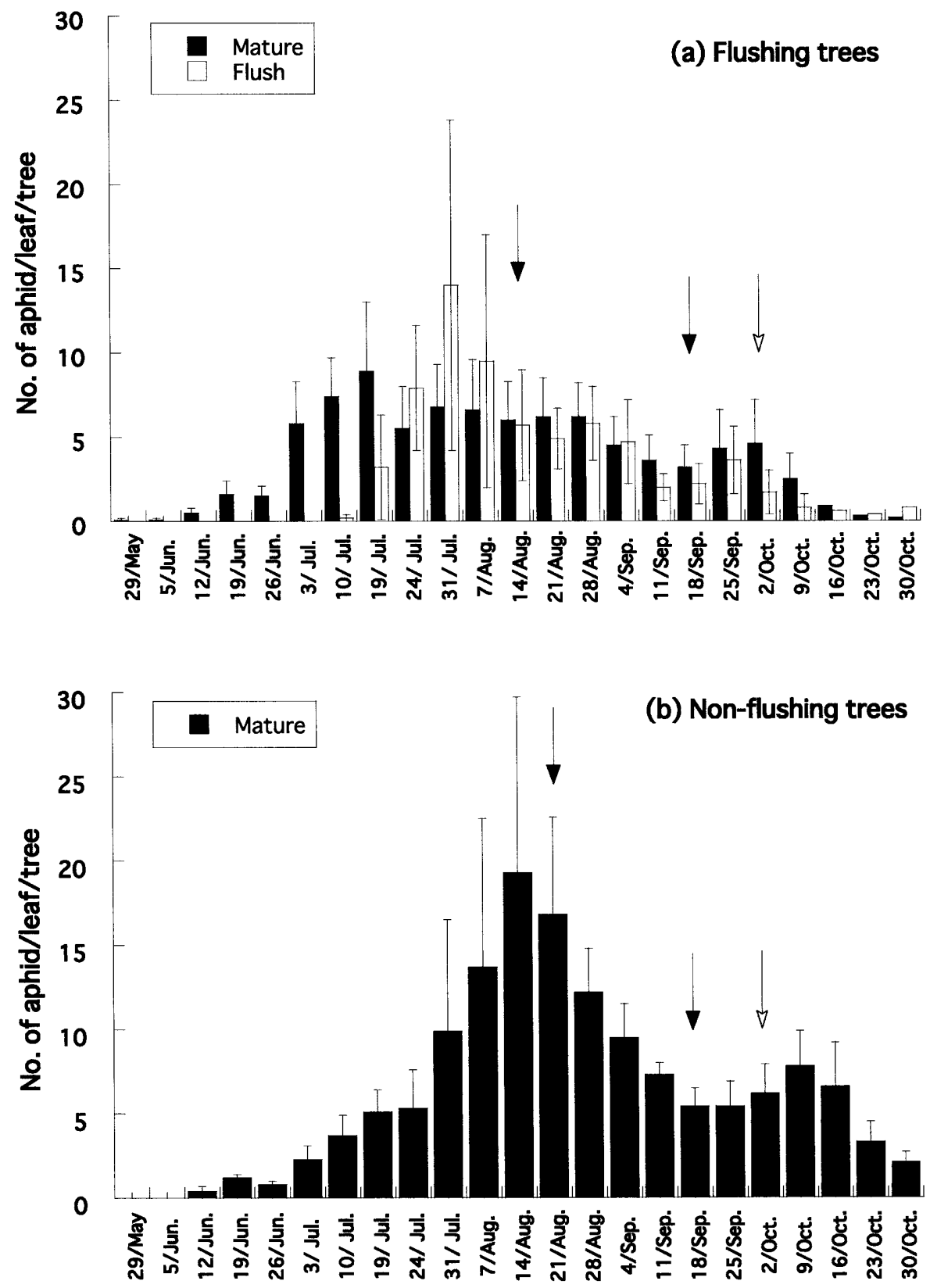

Fig. 1. Seasonal changes in the number of aphids per leaf per tree. In terms of the production of flush leaves in summer, Quercus dentata has two phenotypes: (a) produced flush leaves in mid-July and (b) only produced leaves in spring. Mean \pm SE. Closed arrows indicate the onset and termination of reproductive diapause. Open arrows indicate the appearance of alate males and apterous females.

tem: Solvent A, $0.05 \%$ triethylamine in $0.14 \mathrm{M}$ sodium acetate $(\mathrm{pH} 6.35)$ : acetonitrile $(47: 3 \mathrm{v} / \mathrm{v})$; Solvent $\mathrm{B}$, acetonitrile : water $(3: 2 \mathrm{v} / \mathrm{v})$. Type-H (Wako Co.) was used as the reference amino acid mixture. Asparagine and asparatic acid as well as glutamine and glutamic acid appeared as single peaks on the chromatograms, and thus, were quantified as aspartate and glutamate, respectively. Phenylalanine and tryptophan could not be detected by this method. Cysteine was not included in the statistical analysis because it was present in low amounts in the exudates and honeydew. Arginine, histidine, isoleucine, leucine, lysine, methionine, threonine and valine were pooled as essential amino acids and used in the statistical analysis.

\section{Statistical analysis}

A randomised block ANOVA was used to test for variations in the dependent variables including the amino acid composition of honeydew, the total concentration of amino acids in honeydew, the volume of a honeydew droplet, the number of honeydew droplets and the total volume of honeydew produced. The proportions of amino acids in the phloem sap were analysed using a three-way ANOVA. The effect of treatments on each variable was primarily tested, as well as that of the month of phloem sap or honeydew collection. The month was included as a main effect because the quality of phloem sap could change depending on the time of the experiment. The ANOVA model contained "tree" and "shoot nested within a tree" as blocks. In 
this randomised block design, the interaction terms including those related to shoots and trees were included in the error term (Sokal \& Rohlf, 1995). The main effects, year, month, and treatment were treated as fixed variables. Statistical tests were performed with the JMP package version 5.0.1 J (SAS, 2002).

\section{RESULTS}

\section{Population census}

The aphid population, irrespective of tree type, grew exponentially until early August, followed by a steep decline until late September. Thereafter, the population increased in abundance again (Fig. 1). Of the 20 selected shoots on each of the five trees, 6-13 shoots (average 8.8 shoots) produced secondary shoots with flush leaves. From early July to late July, there were approximately twice as many aphids on flush leaves as on mature leaves (Fig. 1a). After mid-August, no difference was detected in the number of aphids on flush and mature leaves.

\section{Aphid performance on flush and mature leaves}

Fig. 2 shows the combined results of the experiments conducted in 2000 and 2001. Body size and fecundity of aphids that were reared on mature leaves decreased from June to September (Nested ANOVA: body width, $F_{3,42}=$ 37.98, $P<0.0001$,; mature embryo number, $F_{3,42}=6.07$, $P=0.0059$; t total embryo number, $F_{3,42}=7.44, P=$ 0.0024) (Fig. 2). The aphids that developed on flush leaves were larger than those on mature leaves. In addition, the body width, mature embryo number and total embryo number were significantly larger for aphids reared on flush leaves than those on mature leaves (Table 1 and Fig. 2). Over this period none of the dependent variables had a significant effect (Table 1).

\section{Honeydew excretion}

Nested ANOVA indicated that the volume of a honeydew droplet and the total volume of honeydew produced per hour were significantly larger for aphids feeding on flush leaves than on mature leaves (Table 1 and Fig. 3).

\section{Amino acid analysis of phloem sap and honeydew}

The amino acid composition of the exudates from flush and mature leaves did not differ. The three-way ANOVA for each of the amino acids indicated that the proportion of aspartate was significantly higher in flush than in mature leaves (Fig. 4a). Although the mean value for the amino acid concentration was higher for the honeydew produced by aphids reared on flush leaves than on mature leaves, the difference was not significant (Fig. 3d). There was a large variance in the amino acid concentration in the phloem sap of both the flush and mature leaves. The proportions of alanine and glycine were higher in the honeydew produced by the aphids reared on mature than on flush leaves (Fig. 4b).

\section{DISCUSSION}

The present study indicates that aphids feeding on flush leaves in mid-July had a faster rate of development and reproduction, and produced more honeydew than those on mature leaves. However, in mid-summer, regardless of
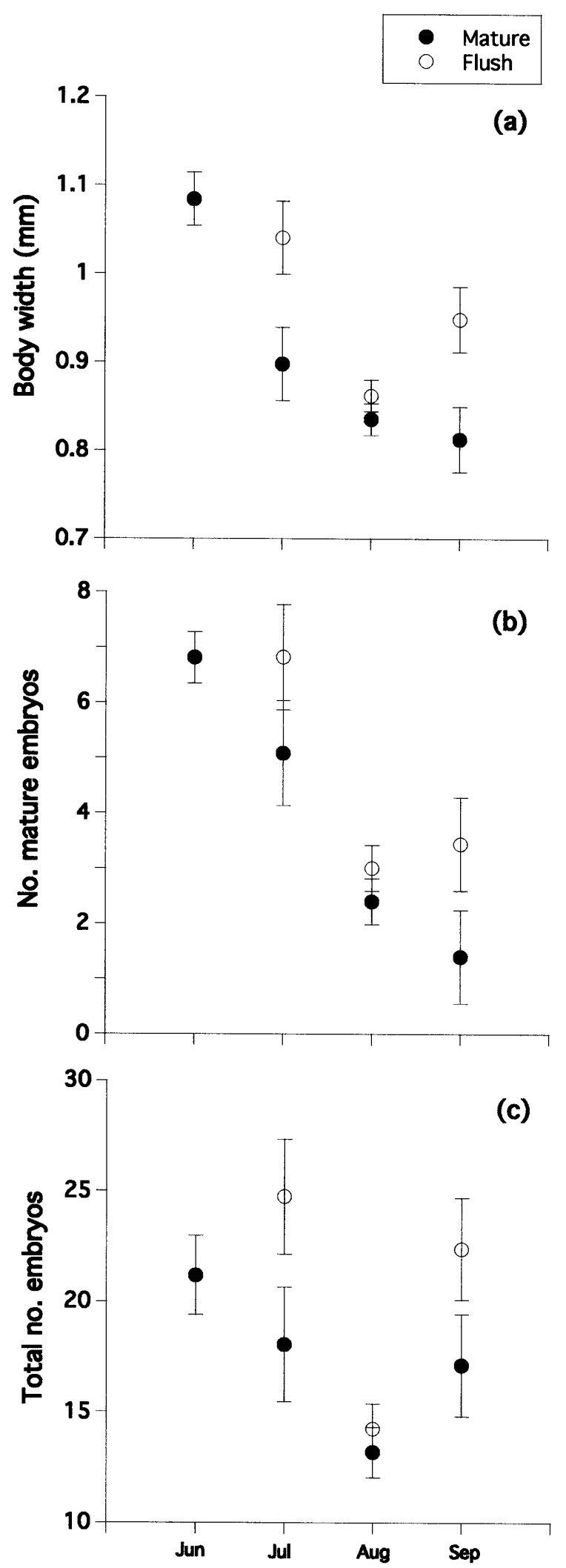

Fig. 2. The effect of rearing aphids on flush and mature leaves from June to September on (a) body width, (b) mature embryo number, and (c) total embryo number in Tuberculatus quercicola. Mean \pm SE. 
TABLE 1. ANOVA of the effect of flush leaves on aphid body size, reproduction, honeydew excretion, and concentration of amino acids in honeydew.

\begin{tabular}{|c|c|c|c|}
\hline & d.f. & $\mathrm{F}$ & $\mathrm{P}$ \\
\hline \multicolumn{4}{|l|}{ Body width } \\
\hline Year & 1 & 0.0967 & 0.7574 \\
\hline Month & 2 & 4.4956 & 0.0167 \\
\hline Tree & 6 & 2.1061 & 0.0716 \\
\hline Shoot (Tree) & 17 & 0.5266 & 0.9242 \\
\hline Leaf & 1 & 14.7556 & 0.0004 \\
\hline Error & 44 & & \\
\hline \multicolumn{4}{|c|}{ No. mature embryos } \\
\hline Year & 1 & 2.0912 & 0.1552 \\
\hline Month & 2 & 6.5605 & 0.0032 \\
\hline Tree & 6 & 0.6005 & 0.7284 \\
\hline Shoot (Tree) & 17 & 1.2934 & 0.2411 \\
\hline Leaf & 1 & 8.2782 & 0.0062 \\
\hline Error & 44 & & \\
\hline \multicolumn{4}{|c|}{ Total no. embryos } \\
\hline Year & 1 & 1.3912 & 0.2445 \\
\hline Month & 2 & 9.3103 & 0.0004 \\
\hline Tree & 6 & 2.0976 & 0.0727 \\
\hline Shoot (Tree) & 17 & 0.6312 & 0.8482 \\
\hline Leaf & 1 & 7.2878 & 0.0098 \\
\hline Error & 44 & & \\
\hline \multicolumn{4}{|c|}{ Volume of honeydew droplet } \\
\hline Tree & 2 & 7.1564 & 0.0080 \\
\hline Shoot (Tree) & 11 & 1.9430 & 0.1273 \\
\hline Leaf & 1 & 5.9321 & 0.0300 \\
\hline Error & 13 & & \\
\hline \multicolumn{4}{|c|}{ Number of droplets } \\
\hline Tree & 2 & 1.5486 & 0.2493 \\
\hline Shoot (Tree) & 11 & 2.5962 & 0.0525 \\
\hline Leaf & 1 & 1.8230 & 0.2000 \\
\hline Error & 13 & & \\
\hline \multicolumn{4}{|c|}{ Total volume of honeydew } \\
\hline Tree & 2 & 6.9574 & 0.0088 \\
\hline Shoot (Tree) & 11 & 1.1353 & 0.4086 \\
\hline Leaf & 1 & 6.9571 & 0.0205 \\
\hline Error & 13 & & \\
\hline \multicolumn{4}{|c|}{ Concentration of amino acids } \\
\hline Year & 1 & 1.4154 & 0.2527 \\
\hline Month & 1 & 0.3174 & 0.5815 \\
\hline Tree & 3 & 2.0128 & 0.1554 \\
\hline Shoot (Tree) & 8 & 0.7266 & 0.6671 \\
\hline Leaf & 1 & 4.4915 & 0.0512 \\
\hline Error & 15 & & \\
\hline
\end{tabular}

leaf type (flush or mature), body size and embryo number decreased, indicating that the aphid was in reproductive diapause. This suggests that although the phloem sap of flush leaves had a better nutritive quality than mature leaves, reproductive diapause in this aphid is programmed, as in the sycamore aphid (Dixon, 1975). The aphids that were transfered from mature to flush leaves in July performed similarly to those on mature leaves in June, indicating that the quality of the phloem sap of flush leaves is equivalent to that of juvenile leaves in early summer. This improvement in nutritive quality is also characterised by an increase in the volume of a honeydew droplet and the total volume of honeydew produced by aphids feeding on flush leaves. The only
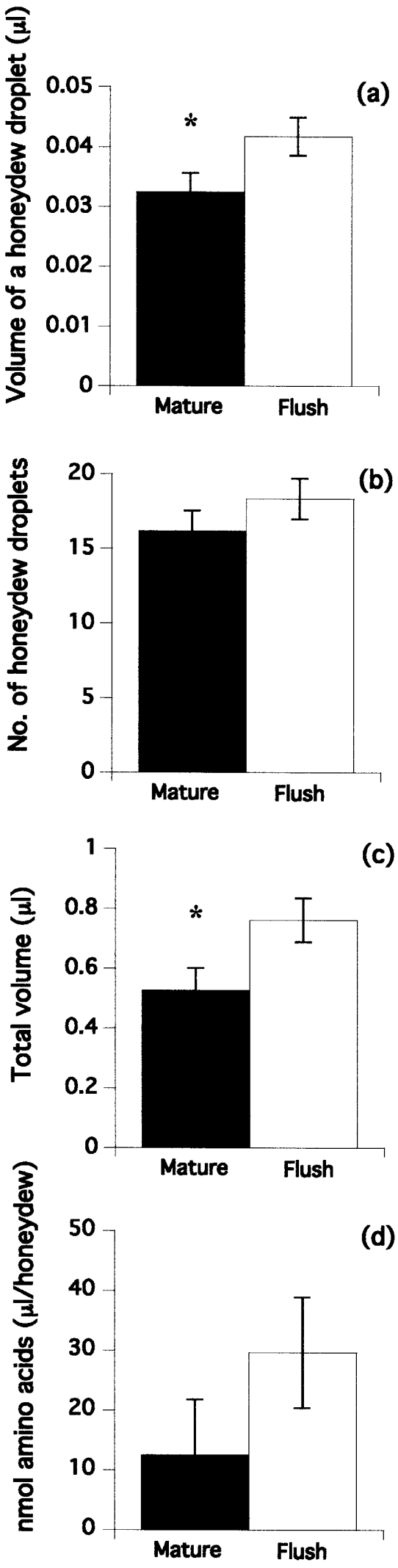

Fig. 3. The effects of flush and mature leaves on (a) volume $(\mu 1)$ of a honeydew droplet, (b) number of honeydew droplets produced per hour, (c) total volume $(\mu \mathrm{l})$ of honeydew produced per hour, and (d) total amino acid concentration in honeydew ( $\mu 1 /$ hondeydew) produced by Tuberculatus quercicola. Mean \pm SE. $* P<0.05$ 

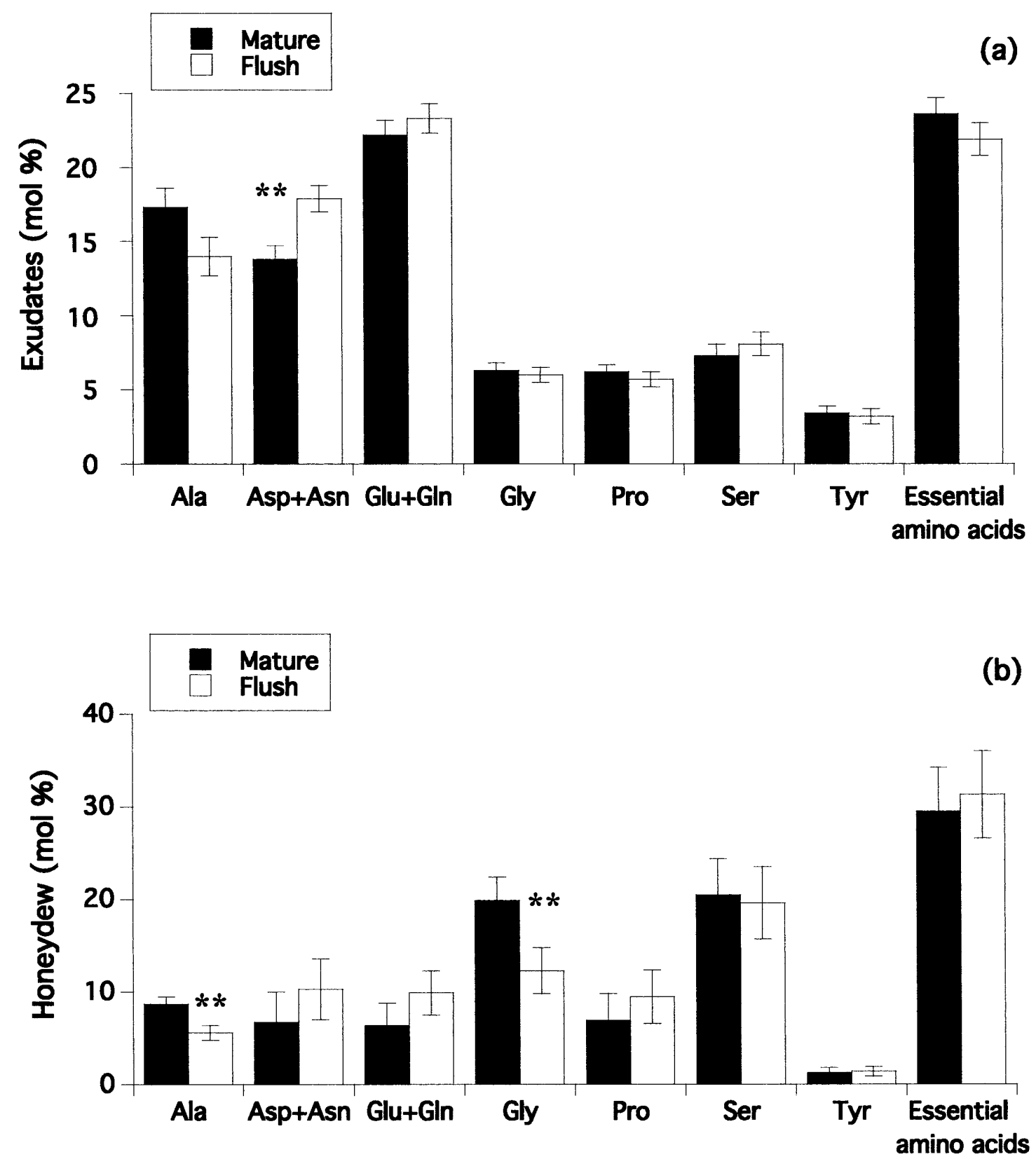

Fig. 4. Amino acid composition of (a) the exudate from flush and mature leaves of Quercus dentata and (b) the honeydew of Tuberculatus quercicola reared on flush and mature leaves. Mean \pm SE. (Randomised block ANOVA with the sequential Bonferroni correction, $* * P<0.005$.)

significant difference in the amino acid composition of phloem sap of flush and mature leaves was in aspartate. In addition to this difference in amino acid composition, an increase in leaf toughness and a decrease in water content in summer (Shibata et al., 2001) may also contribute to the difference in the performance of $T$. quercicola on flush and mature leaves.

High relative levels of aspartate in phloem sap may account for the better aphid performance on flush leaves. In some species of pea, asparagine functions as a carrier for protein nitrogen and provides the nitrogen necessary for amino acid synthesis during germination (Conn et al., 1987). A similar amino acid synthesis with respect to elongation of secondary shoots may be responsible for the higher concentration of aspartate in flush leaves. Aspartate, which is ingested by aphids, is recycled via the symbiotic bacterium Buchnera in the form of essential amino acids for the aphids (Sasaki \& Ishikawa, 1993).

The difference in the number of aphids on flush and mature leaves (Fig. 1a) appears to reflect the difference in the total embryo number of the aphids (Fig. 2). Although the greater number of aphids on flush leaves did not extend up to September, the rapid propagation of aphids in colonies on flush leaves immediately after bud burst may increase their chances of surviving the nutritional stress in summer. 
Migrating to flush leaves is an effective way of improving reproduction or development in T. quercicola, however, this aphid does not depend on secondary leaf production because flush leaves are an unpredictable resource and possibly occur too early in the year to completely offset the effect of leaf maturation. There is a large variation in the number of flush leaves produced by different individuals of $Q$. dentata, which depend on the average summer temperature and level of defoliation in spring (Yao unpubl.). In addition, colonies of T. quercicola survived up to October even on $Q$. dentata trees that did not produce secondary leaves (Fig. 1b). Thus, it is unlikely that flush leaves play a critical role in the survival of $T$. quercicola.

Given that the body size and total embryo number of the aphids decreased in summer and increased in September (Fig. 2), the aphids appear to have entered reproductive diapause regardless of whether they were reared on flush or mature leaves. This is similar to what is recorded for the sycamore aphids, $D$. platanoidis and $P$. testudinaceus, as well as Thelaxes dryophila on oak, which aestivate in summer (Dixon, 1970; Shearer, 1976; Dixon, 1998). During this period, individuals have a high fat content, poorly developed gonads, long gut, and low metabolic rate. Since the decline in the nutritional status of phloem sap occurs at approximately the same time each year, the regularity enables $T$. quercicola to anticipate the onset of unfavourable conditions. Therefore, the strategy of reproductive diapause is more likely to be favoured by selection than the use of flush leaves. Although it remains to be shown that reproductive diapause in $T$. quercicola is a consequence of the lower nutritional quality of phloem sap or a programmed reproductive strategy, reproductive diapause is a key element in the life cycle of T. quercicola.

Non host-alternating aphids have developed the following mechanisms for avoiding the nutritional stress that occur on woody hosts in mid-summer, gall formation (Kennedy, 1958; Forrest, 1971; Koyama et al., 2004), life cycle shortening (Akimoto, 1985; Eastop, 1986; vonDohlen \& Gill, 1989), aestivation (Dixon, 1970), migration to other feeding sites on the same host plant (Dixon, 1998), or changes in morph characteristics such as the length of the gut or proboscis (Dixon, 1998). This study demonstrates that the use of flush leaves does not enable T. quercicola to avoid the nutritional stress in summer and not enter reproductive diapause. Further, this study may contribute to a better understanding of the strategy employed by non host-alternating aphids.

ACKNOWLEDGEMENTS. Thanks are due to Y. Abe for technical help with the amino acid analysis. This study was financially supported by a JSPS Research Fellowship for Young Scientists and by the $21^{\text {st }}$ Century Center of Excellence Program on "Neoscience of Natural History" at Hokkaido University, financed by the Japan Society of the Promotion of Science.

\section{REFERENCES}

Акімото S. 1985: Taxonomic study on gall aphids, Colopha, Paracolopha and Kaltenbachiella (Aphidoidea: Pemphigidae) in East Asia, with special reference to their origins and distributional patterns. Insec. Matsu. 31: 1-79.

Awmack C.S. \& Leather S.R. 2002: Host plant quality and fecundity in herbivorous insects. Annu. Rev. Entomol. 47: 817-844.

Conn E.E., StumpF P.K., Bruening G. \& DoI R.H. 1987: Outlines of Biochemistry. 5th ed. John Wiley \& Sons, New York, $693 \mathrm{pp}$.

DAGG J.L. 1999: Plant-induced change in the life-cycle of the pine aphid Schizolachnus pineti. Ecol. Entomol. 24: 484-485.

Dixon A.F.G. 1970: Quality and availability of food for a sycamore aphid population. In Watson A. (ed.): Animal Population in Relation to their Food Resources. Blackwell, Oxford, pp. 229-247.

DiXon A.F.G. 1975: Seasonal changes in fat content, form, state of gonads and length of adult life in the sycamore aphid, Drepanosiphum platanoides (Schr.). Trans. R. Entomol. Soc. Lond. 127: 87-99.

Dixon A.F.G. 1998: Aphid Ecology, An Optimisation Approach. 2nd ed. Chapman \& Hall, London, 300 pp.

Douglas A.E. 1993: The nutritional quality of phloem sap utilized by natural aphid populations. Ecol. Entomol. 18: 31-38.

EASTOP V.F. 1973: Deductions from the present day host plants of aphids and related insects. In Van Emden H.F. (ed.): Insect/Plant Relationships. Symposium of the Royal Entomological Society of London 6. Blackwell Scientific Publications, Oxford, pp. 157-178.

Eastop V.F. 1986: Aphid-Plant Associations. Coevolution and Systematics. Clarendon Press, Oxford, pp. 33-54.

FEENy P. 1970: Seasonal changes in oak leaf tannins and nutrients as a cause of spring feeding by winter moth caterpillars. Ecology 51: 565-581.

FoRREST J.M.S. 1971: The growth of Aphis fabae as an indicator of the nutritional advantage of galling to the apple aphid Dysaphis devecta. Entomol. Exp. Appl. 14: 477-483.

INOUE T. 1998: Life history of the flea beetle, Argopistes coccinelliformis Csiki (Coleoptera: Chrysomelidae) VI. Overwintering and oviposition abilities of adults which emerged late in the season. Appl. Entomol. Zool. 33: 21-27.

KenNEDY J.S. 1958: Physiological condition of the host-plant and susceptibility to aphid attack. Entomol. Exp. Appl. 1: $50-65$.

King R.W. \& ZeEvaArt J.A.D. 1974: Enhancement of phloem exudation from cut petioles by chelating agents. Plant. Physiol. 53: 96-103.

Kоуама Y., Yао I. \& Акімото S. 2004: Aphid galls accumulate high concentration of amino acids: a support for the nutrition hypothesis for gall formation. Entomol. Exp. Appl. 113: $35-44$.

SAS 2002: JMP, 5.0.1J. SAS Institute, Cary, North Carolina.

SASAKI T. \& IshIKAWA H. 1993: Nitrogen recycling in the endosymbiotic system of the pea aphid, Acyrthosiphon pisum. Zool. Sci. 10: 779-785.

SheArer J.W. 1976: Polymorphism and Population Ecology of European Maple Aphid, Periphyllus testudinaceus (Fernie). $\mathrm{PhD}$ Thesis. University of Glasgow.

Shibata S., Ishida T.A., Soeya F., Morino N., Yoshida K., Sato H. \& KimURA M.T. 2001: Within-tree variation in density and survival of leafminers on oak Quercus dentata. Ecol. Res. 16: 135-143.

SoKAl R.R. \& RohlF F.J. 1995: Biometry. 3rd ed. Freeman, New York, 887 pp.

Von Dohlen C.D. \& GiLl D.E. 1989: Geographic variation and evolution in the life cycle of the witch-hazel leaf gall aphid, Hormaphis hamamelidis. Oecologia 78: 165-175. 
Weibull J., Ronguist F. \& Brishammar S. 1990: Free amino acid composition of leaf exudates and phloem sap. Plant. Physiol. 92: 222-226.

Yао I. \& Акімото S. 2001: Ant attendance changes the sugar composition of the honeydew of the drepanosiphid aphid Tuberculatus quercicola. Oecologia 128: 36-43.

Yао I. \& Акімото S. 2002: Flexibility in the composition and concentration of amino acids in honeydew of the drepanosi- phid aphid Tuberculatus quercicola. Ecol. Entomol. 27: 745-752.

Yao I., Shibao H. \& Акiмoto S. 2000: Costs and benefits of ant attendance to the drepanosiphid aphid Tuberculatus quercicola. Oikos 89: 3-10.

Received January 6, 2004; revised August 10, 2004; accepted September 13, 2004 